\title{
Gender verification in sports by PCR amplification of SRY and DYZ1 Y chromosome specific sequences: presence of DYZ1 repeat in female athletes
}

Angels Serrat, Antonio García de Herreros

\begin{abstract}
Objective-To perform genetic sex typing during the Barcelona Olympic Games using polymerase chain reaction (PCR) amplification of $Y$ chromosome specific sequences.

Methods-The assay consisted of the amplification of a specific sequence corresponding to the repeat DYZ1 element from buccal smears samples of 2406 female competitors. Positive samples were reanalysed for the presence of another $Y$ chromosome specific gene, SRY.

Results-The expression of these two elements did not always correlate; six samples were found where the presence of DYZ1 but not SRY was detected. This presence of DYZ1 sequence in female athletes is higher than in unselected females, where no DYZ1 amplification was observed in any of the 1629 samples analysed.

Conclusions-Amplification of DYZ1 repeat should not be used as the only index for determining genetic sex, at least in sporting events.
\end{abstract}

(Br F Sports Med 1996;30:310-312)

Key terms: PCR; sex typing; sporting event

Gender verification of Olympic athletes has been a matter for discussion since the first analyses were performed. ${ }^{1}$ In 1991 , following the recommendations of Dingeon and other scientists, ${ }^{2}$ the International Olympic Committee (IOC) decided to include in the protocol for gender verification a step based in the amplification by the polymerase chain reaction (PCR) of $\mathrm{Y}$ chromosome specific sequences (Y-PCR). Several sequences are currently used for sex typing; one of the methods takes advantage of the high abundance in $\mathrm{Y}$ chromosome long arm of a $3.4 \mathrm{~kb}$ specific repeat (DYZ1 repeat). ${ }^{3}$ Determination of the presence of the DYZ1 repeat, initially by dot blot hybridisation ${ }^{4}$ and later by PCR amplification, ${ }^{5}$ has been used for sex typing. On the other hand, increasing evidence obtained from experimental animals supports the idea that the testis determining factor is the product of the single copy gene SRY. ${ }^{67}$ As part of the programme of the IOC to determine genetic sex, we studied the presence of these markers in female competitors in the Barcelona Olympic
Games by PCR amplification of Y chromosome specific sequences. With the aim of responding to the many requests received by different scientists, we report here the protocol used in these analyses and their results. A brief description of these results and the criteria followed by the IOC have been already published. ${ }^{8}$

\section{Methods}

COLLECTION AND PROCESSING OF SAMPLES

All the operations were carried out by female officials in areas specially allocated where men were not allowed. Buccal smears samples from both sides of the mouth (samples $\boldsymbol{a}$ and $\boldsymbol{b}$ ) of each competitor were taken with a sterile filtered tip and deposited on $100 \mathrm{ml}$ of sterile water. Tubes were labelled and introduced into a box, on the top of which another label with the same number was attached. The fourth identical label was attached to the identification key sheet that was picked up twice a day by a messenger from the organising committee of the Barcelona Olympic Games (COOB). The box containing the samples was sent to the laboratory at 2 and $8 \mathrm{pm}$. The general scheme of the test is shown in fig 1 .

Sample $\boldsymbol{a}$ was boiled for 10 minutes, spun down in a microfuge, and PCR amplification of a sequence specific for the DYZ1 repeated element was performed as indicated below from $10 \mathrm{ml}$ of total extract. An internal control was always included in our experiments, using two oligos, M1-M2, specific for mitochondrial DNA. ${ }^{9}$ Samples that showed amplification of the DYZ1 fragment (positive result) or those that did not show amplification either of DYZ1 or Mito fragment (not determined result) were subjected to further analyses (see fig 2). In this case, DNA was purified from the two samples obtained from the same individual using a DNA purification kit commercialised by Linus (Madrid, Spain). These two samples were used as templates in two parallel reactions of amplification, one with D1-D2 (for DYZ1) and M1-M2 (for mitochondrial fragment) primers and another with S1-S2 (for SRY) primers (see fig 3). Only those samples that showed amplification of both D1-D2 and S1-S2 were reported as "positives" to the COOB. These positive results were communicated personally, in order to maintain confidentiality of the results of the assay. The whole process took four to five hours and never lasted longer than 36 hours. 


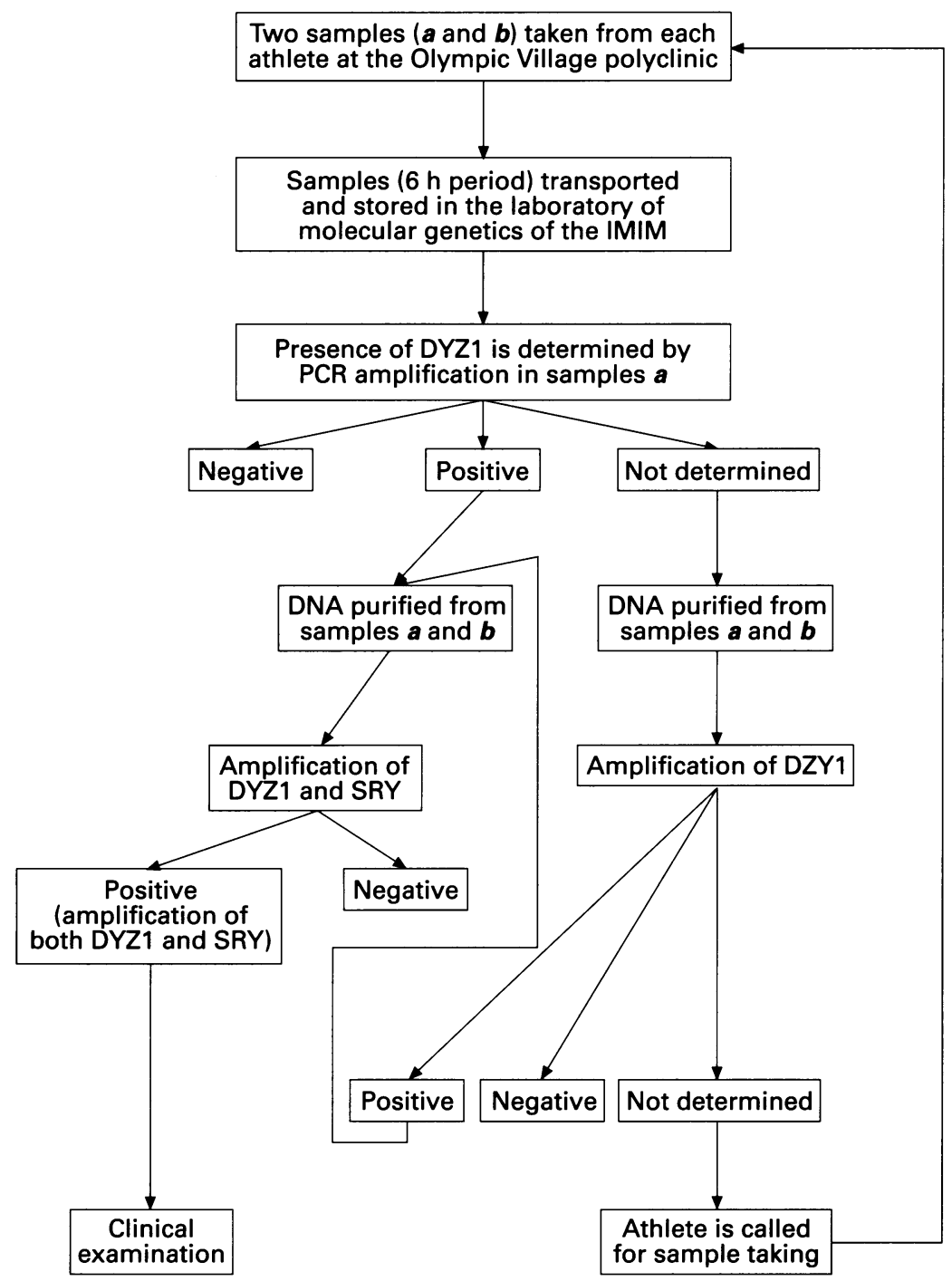

Figure 1 General scheme for Olympic Games gender verification test. For details see text.

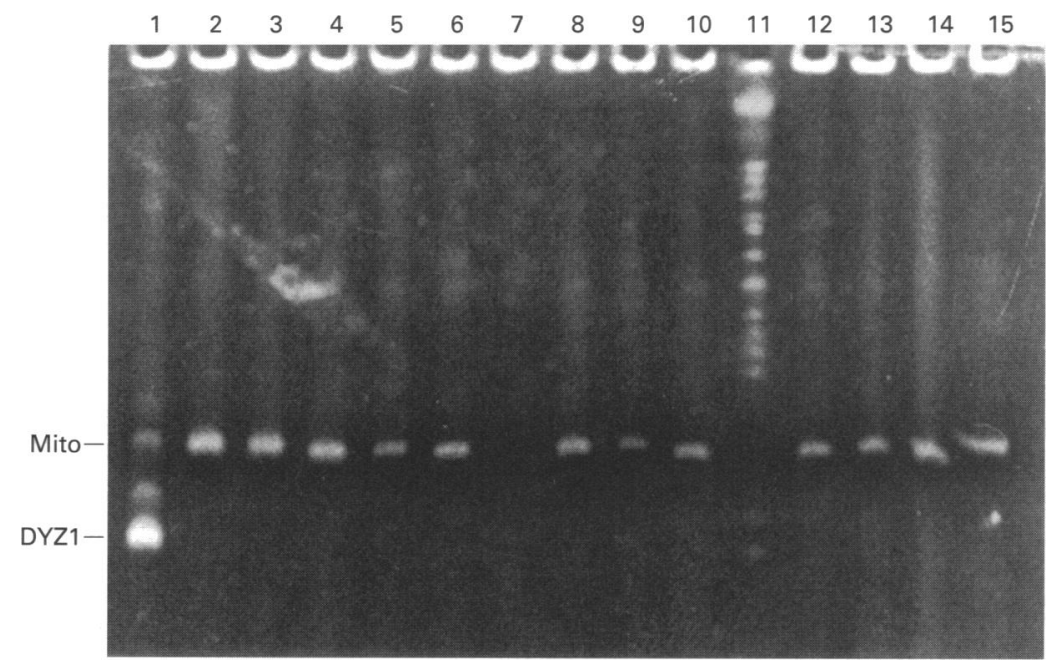

Figure 2 First screening: amplification of DYZ1 in female samples. Lane 1, female sample showing DYZ1 amplification. Lanes 2 to 6, 8 to 10 and 12 to 15, female samples showing amplification of mitochondrial DNA only. Lane 7, not determined sample. Lane 11, molecular weight marker. Samples from lanes 1, 7 and its duplicates pass to the second screening where DNA is amplified with oligos S1-S2 and D1-D2.

Negative (no DNA) and positive (male DNA) controls were always added to the assays and to the DNA purification procedure; approximately one negative control for every 15 analysed samples and one positive control for every 30. Preparation of the samples, amplification, and analysis of the reactions were performed in three different rooms with permanently allocated material. Pipettes and filtered tips for PCR were kept under UV light for 30 minutes before setting the reactions. In all our analyses, controls always showed up as predicted; no cross contamination problems were detected. Duplicate samples ( $\boldsymbol{a}$ and $\boldsymbol{b}$ ) always reported identical results.

PCR AMPLIFICATION AND ANALYSIS OF PRODUCTS Reactions of amplification were performed in $20 \mathrm{ml}$ using standard conditions $(10 \mathrm{mM}$ Tris$\mathrm{HCl}, \mathrm{pH} 8.3 ; 50 \mathrm{mM} \mathrm{KCl} ; 1.5 \mathrm{mM} \mathrm{MgCl}$; $200 \mathrm{mM}$ of each dNTP) with $50 \mathrm{ng}$ of each primer (D1-D2 and M1-M2) or $150 \mathrm{ng}$ (S1-S2), and 0.8 units of AmpliTaq DNA polymerase (Perkin Elmer). Ten microlitres of a total lysate of the buccal smear (from $100 \mathrm{ml}$ total) were used as template. Samples were subjected to 43 cycles $\left(95^{\circ} \mathrm{C}-15 \mathrm{~s}, 50^{\circ} \mathrm{C}-15\right.$ $\mathrm{s}, 72^{\circ} \mathrm{C}-20 \mathrm{~s}$ ) with a final polymerisation step of three minutes at $72^{\circ} \mathrm{C}$, in a GeneAmp PCR System 9600 thermocycler from Perkin Elmer Instruments. The presence of the amplified sequence was checked by electrophoresis in gels of polyacrylamide $(6 \%)$ in TBE buffer (89 $\mathrm{mM}$ Tris-borate, $\mathrm{pH} 8.3 ; 2 \mathrm{mM}$ EDTA) and staining in ethidium bromide $\left(0.5 \mathrm{mg} \mathrm{ml}^{-1}\right.$ for 10 minutes).

\section{Results and discussion}

We describe here the assay used in Barcelona Olympic Games for genetic sex determination. This assay was performed in two steps: in the first screening, the presence of the DYZ1 repeat was analysed in total lysates of buccal smears taken from the female competitors, using primers D1-D2. As an internal control, coamplification of a sequence specific for mitochondrial DNA was performed using primers M1-M2. The quickness of this assay allowed us to obtain results within four hours after the arrival of the sample, since no DNA purification was required. In our previous studies, amplification of DYZ1 specific sequences was detected in $100 \%$ of the control male samples (89/89), and in none of 1629 female samples. However, when the female competitors from the Barcelona Olympic Games were analysed with this assay, 11 samples rendered a positive result (11/2406; $0.46 \%)$. In a second screening, SRY and DYZ1 specific sequences were amplified from purified DNA from these 11 samples, using primers S1-S2 and D1-D2. Five of these 11 samples showed the presence of the SRY specific sequence. According to the criteria of the IOC Medical Commission that only SRY and DYZ1 positive athletes were considered for further analysis, only these five competitors were subjected to a physical examination. In the remaining six cases, amplification of DYZ1 was detected but not that of SRY; a representative case is shown in fig 4 (sample \$2). Identical results were obtained in duplicate samples from the same subjects.

The Y-PCR assay used to determine genetic sex in Barcelona Olympic Games was performed in two steps. A first screening deter- 


\section{Locus Oligos sequence}

DYZ1 D1: 5'-TCC ACT TTA TTC CAG GCC TGT-3

D2: 5'-TTG AAT GGA ATG GGA ACG AAT-3'

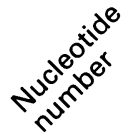

$3511-3531$

$100-80$

30-150

300-279
$171 \mathrm{bp}$

$150 \mathrm{bp}$ Kogan

$(1987)^{5}$

Gubbay

$(1990)^{6}$

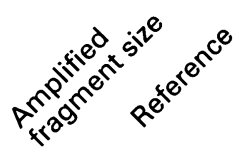

Mito

M1: 5'-ACG TCT TGC ACT CAT GAG CTG T-3' $\quad$ 8058-8079

M2: 5'-TGC TAA GTT AGC TाT ACA GTG G-3' $\quad$ 8315-8294

257 bp Anderson

$(1981)^{9}$

Figure 3 Oligonucleotides used for the amplification of DYZ1, SRY, and mitochondrial specific sequences. The table shows the oligonucleotides primers used to analyse the three loci, with their localisation (nucleotide number) in the sequence indicated in the corresponding reference. It is also shown the size of the amplified fragment in each case.

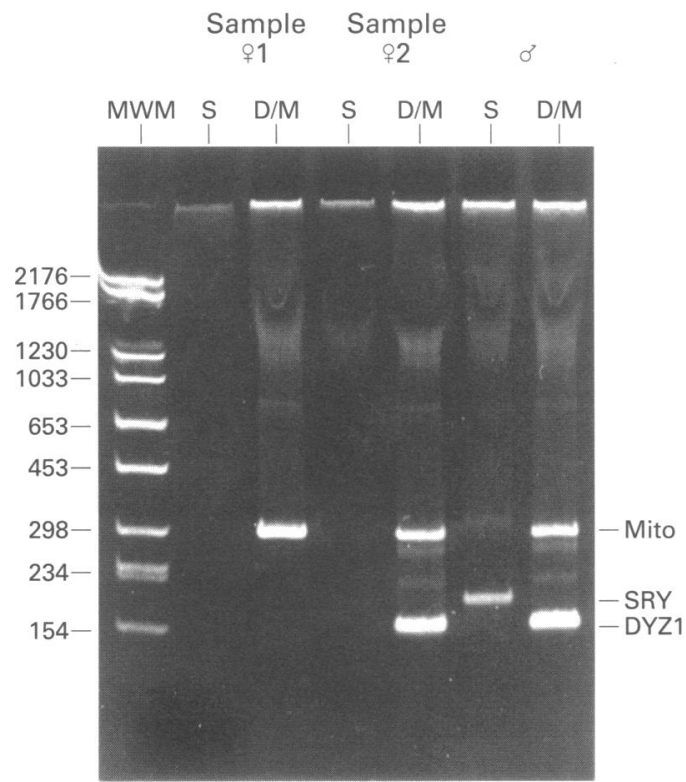

Figure 4 Lack of correlation between the amplification of DYZ1 and SRY specific sequences. o, control male sample; $\uparrow 1$, control female sample; $\$ 2$, female sample showing amplification of DYZ1 specific sequence but not that of SRY.

mined the presence of DYZ1 by PCR amplification from total cell lysates. However, the positive cases had to be double checked for SRY presence because some samples that were DYZ1 positive did not yield SRY amplification products. The reasons for this discrepancy are still unknown since reasons of ethics did not allow us to perform a more extensive analysis of these samples, which were destroyed after the competition. Two plausible explanations are as follows. (1) Due to the high number of DYZ1 repeats in the male genome, it is likely that samples are more prone to be contaminated for DYZ1 that for SRY gene. However, it should be pointed out that very strict conditions were taken to prevent contaminations (for instance, only female officials were involved in the sampling and processing) and contaminations were never detected in our previous extensive analyses. (2) It is also possible that these samples correspond to athletes who had suffered a partial translocation of $\mathrm{Y}$ chromosome. Unfortunately, the athletes were not identified and further studies could not be performed, but it would have been interesting to have been able to prove this hypothesis. If this second possibility were correct, our analysis would also suggest a more widespread presence of DYZ1 in athletes than in the general female population, although the number of cases analysed was not enough statistically to conclude that there was a higher prevalence. However, it is also possible that the differences in the presence of DYZ1 might arise from other alternative explanations, as the ethnic diversity of the competitors.

Due to the high copy number of the DYZ1 repeat in the $\mathrm{Y}$ chromosome, amplification of sequences specific for this element has been used to study genetic sex in samples containing very few cells by FISH and NISH techniques. ${ }^{1011}$ Our results suggest that the use of DYZ1 as marker of genetic sex might lead to errors in the classification of the samples, at least in sports competitors, and recommend the use of SRY sequences for genetic sex typing.

The technical assistance of Coral Ampurdanés, Elisabet Carrillo, and Rosa M. Martinez is greatly appreciated. We thank Dr Francisco Real for his support and Dr Bernard Dingeon for his advice on some technical aspects of the assay. We also thank all the laboratory members for their help in some critical moments of the study. This work was supported by a contract from the COOB 92 .

1 Simpson JL, Ljungqvist A, de la Chapelle A, FergusonSmith MA, Genel M, Carlson AS, et al. Gender verification in competitive sports. Sports Med 1993;16:305-15.

2 Dingeon B, Amor Gueret $M$, Vercherat $M$, Schamasch P, Thome H. In: Workshop on the Approved Method for Feminity Verification; November 10-11, 1990; Mona

3 Nakahori Y, Mitani K, Yamada M, Nakagome Y. A human Y-cahori Y, Mitani K, Yamada M, Nakagome Y. A human Y-chromosome specific repeated DNA family (DYZ1) consists of a tandem array of pentanucleotides. Nucleic
Acids Res 1986;14:7569-80 Acids Res 1986,14:756

4 Lau Y-F, Huang JC, Dozy AM, Kan YW. A rapid screening test for antenatal sex dermination. Lancet 1984;i:14-16.

5 Kogan SC, Doherty M, Gitschier J. An improved method for prenatal diagnosis of genetic diseases by analysis of amplified DNA sequences. $N$ Engl $\mathcal{F}$ Med 1987;317:98590

6 Gubbay J, Collignon J, Koopman P, Capel B, Economou A, Münsterberg A, et al. A gene mapping to the sexdetermining region of the mouse $\mathrm{Y}$ chromosome is a member of a novel family of embryonically expressed genes. Nature 1990;346:245-50.

7 Koopman P, Gubbay J, Vivian N, Goodfellow P, LovellBadge R. Male development of chromosomally female mice transgenic for Sry. Nature 1991;351:117-21.

8 Serrat A, Garcia de Herreros A. Determination of genetic sex by PCR amplification of Y-chromosome-specific sex by PCR amplification of

9 Anderson S, Bankier AT, Barrell BG, de Bruijn MHL, Coulson AR, Drouin J, et al. Sequence and organization of Coulson AR, Drouin J, et al. Sequence and organization of 65.

10 Mori C, Shiota K. Sexing of human embryos and fetuses by fluorescent in situ hybridization (FISH) to paraffinembedded tissues with sex chromosome-specific DNA probes. Am f Med Genet 1994;50:180-6.

11 Betz P, Baretton G, Tubel J, Nerlich A, Eisenmenger W. Morphological detection of $\mathrm{X}$ - and Y-chromosomes in smears and paraffin-embedded tissues using a non-isotopic in situ hibridization technique (NISH). Int $\mathcal{F}$ Legal Med 1994;107:108-10. 